\title{
The Changes in Massive Open Online Courses (MOOCs) Studies between 2012 and 2017- A Review of Literature
}

\author{
Abdulaziz, A, Alzahrani ${ }^{1, *}$ \\ ${ }^{1}$ Instructional Technology Department, University of Ha’il, Ha’il, Saudi Arabia \\ *Correspondence: Instructional Technology Department, University of Ha’il, Ha’il, Saudi Arabia. E-mail: \\ ab.alzahrani@uoh.edu.sa
}

Received: June 30, 2018

Accepted: July 9, 2018 Online Published: August 3, 2018

doi:10.5430/wje.v8n4p59

URL: https://doi.org/10.5430/wje.v8n4p59

\begin{abstract}
In recent decades, the use of Massive Open Online Courses (MOOCs) has changed according to the different goals and studies that have been applied. Therefore, it is very important to explore and examine these changes and identify the development of use and conception of MOOCs. This research is considered empirical in nature and focuses on studies published between 2012 and 2017. The current study is conducted on three scientific databases to collect those studies that matched the research method and achieved its goal. Nine hundred seventy-nine studies were considered, and 37 studies have been selected for this study and will be analyzed based on study design and other variables. The collected studies utilized the qualitative method, quantitative method, and mixed-method approaches. These studies were analyzed through the use of MOOCs according to students' views, instructors' views, and students' and instructors' views. The results showed a different understanding of MOOCs between the students' views, instructors' views, and students' and instructors' views. Recommendations and future research opportunities are also discussed.
\end{abstract}

Keywords: Massive Open Online Courses, students’ view, instructors’ view

\section{Introduction}

MOOCs are considered a new concept, whereby course material reaches a much wider range of learners. These learners organize based on their affinity or languages. This helps them to better exchange ideas, share thoughts, and effectively solve many of the hardships that they experience when learning (Epelboin, 2013). However, there has currently been significant debate regarding these courses, such as the media attention it has received, and the amount of attention it has gotten from various stakeholders, including institutions of higher learning (Najafi, Evans \& Federico, 2014).

Given the modern developments resulting from the constant progress of the technological world, there seems to be no limit as to what education might look like in the future. This is already evident, as online learning has played a key role in the development of many individuals who can achieve personal development at a very high rate (Bucovetchi et al., 2015).

\subsection{Massive Open Online Course}

MOOC is an abbreviation for Massive Open Online Course, which is a free web-based course that can be accessed by anyone across the world (Espinosa, Sepulveda \& Montoya, 2015; Cormier \& Siemens, 2010; Kop \& Carroll, 2011; Nkuyubwatsi, 2013). The participants in a MOOC are able to access the highest quality of learning materials being offered by the top universities worldwide. Many researchers define MOOCs as providing individuals with access to the learning materials from world-class institutions without necessarily having to attain any form of entry requirements and is easily accessible via the internet (Barak, Watted \& Haick, 2016).

The origin of the word MOOC is attributed to Cormier who is working as a manager of web communication and innovations at the University of Prince Edward Island, who started the concept for "a large online class taught by Siemens and Downes in 2008" (Khalil \& Ebner, 2015, p 630). However, Siemens and Downes also thought of MOOCs being an environment that is suitable for connectivity. This was a form of teaching that would be focused on the creation of networks between the students based on the platform of the shared content. In addition to the creation 
of social networking tools, it would enhance future student-to-student interaction and collaboration. Consequently, MOOCs became a platform of free access to quality courses (Espinosa, Sepúlveda, \& Montoya, 2015), which can effectively drive down the cost of university education (McAuley et al., 2010). The use of MOOCs was further compounded by its two key features - open accessibility and scalability (Khalil \& Ebner, 2015).

With these aspects in place, MOOCs were set to become a learning avenue where experts in different fields would present in their areas of expertise in the form of videos to students interested in that area. These experts would present their areas of specialization over a particular period of time, just like a normal class at a university. These courses cover some technical subjects and courses in social sciences and humanities (Khalil \& Ebner, 2015). In the MOOC system, there would be online video tutorials, quizzes, and special forums that would be aimed at encouraging student participation (Khalil \& Ebner, 2015). This would all be done with very minimal involvement of the instructor. This method of passing knowledge is beneficial to the whole world, as it greatly helps those who couldn't attend courses to higher education. Due to the presence of so many learners, many platforms have been created to "make teaching, learning resources, and courses" in the different areas of specialization "available online" (Khalil \& Ebner, 2015, p 630). There are some examples of the most important platforms such as Udacity, Coursera, edX, Udemy, and the Khan Academy. All these different sites have one thing in common - the provision of opportunity for students to learn from experts, fellow peers, and other people outside a traditional university setting (Khalil \& Ebner, 2015).

In fact, MOOCs have always been seen as standalone types of courses, but the recent uptake of it in institutional learning has created the need for a possible merger with a more traditional system of learning in which the MOOCs will be combined with face-to-face learning, although the creation of a blended version might create some conflict in terms of what the students learn online versus what they are being taught in the institutions themselves (Bucovetchi et al., 2015). This is because it is harder to fit "in-class modules into an existing MOOC in a way that optimizes student engagement, satisfaction, and overall learning” (Bruff, Fisher, McEwen \& Smith, 2013, p. 188).

Over the years, the use of MOOCs has sparked massive debates. One of the major points of contention is the constant issue of quality in the MOOCs, while others might say that MOOCs are generally good because they provide a great knowledge base for entire populations. This is supported by the fact that they provide each person with opportunities to engage with the materials via formative assessments and give them the ability to adjust their learning environment (Nkuyubwatsi, 2013). An example of this comes from Stanford University, wherein the students prefer taking artificial intelligence (AI) courses in the form of a MOOC as opposed to a traditional classroom setting. However, MOOCs are also highly criticized for their lack of feedback and their low levels of comprehensibility. This has led to a low completion rate of MOOCs, largely caused by the lack of critical creative thinking by the students. In addition to that, the contribution of MOOCs in developing countries as a means of accessing higher education is greatly opposed by some institutions (Koller, 2012).

\section{Purpose of the Study}

The aim of this study is to provide a current review of the understanding regarding the use of MOOCs based on the views of students and instructors and how those perspectives have developed from January 2013 to July 2017. This study presents the changes in carefully selected studies from January 2013 to 2017 with different research implications. It also investigates the diversity of the methodologies used by previous researchers in the area of MOOCs. The study is interested in presenting the areas and findings of what previous research examined and explored regarding the use of MOOCs. It is important to provide an analysis of the students' and instructors' views of using MOOCs in order to determine how they have been viewed from their beginning to the present time. Suggestions for future research in the area of MOOCs also discussed that will lead to more in-depth findings.

\section{Methodology}

The research was conducted on three scientific databases (Springer, IEEE, and ProQuest) and was limited to peer-reviewed articles and dissertations published between January 2013 and July 2017. The researcher collected the data by using the search bar in the three mentioned search engines to find research related to the target topic. The researcher then used the words MOOC+ students' views / MOOC+ learners' views / MOOC+ teachers' views / MOOC+ perspectives to find articles related to the topic. Moreover, the researcher specified the dates of his search from January 2013 to July 2017. Following that, he collected all the results of his search and classified the studies as defining MOOC, students' views, and instructors' views. All abstracts of the articles were screened to ensure that the articles were related to the purpose of this study. Moreover, all the results included in this study were discussed by 
the researcher. The results showed that there were differences in the students' and instructors' opinions according to the articles selected in this study. Table 1 presents the summary of the results arrived at by the researcher and presented in this review. According to the applied methodology, there are 15 studies that applied a quantitative method (40.54\%), 12 studies that used mixed methods (32.43\%), and 10 studies that applied a qualitative method (27.03\%). Moreover, most of the studies considered the students' views of MOOCs ( $n=24 ; 64.86 \%)$, students' and instructors' views of MOOCs ( $n=7 ; 18.92 \%)$, and instructors' views of MOOCs $(n=5 ; 13.51 \%)$.

Table 1. Overview of the Studies

\begin{tabular}{|c|c|c|c|c|}
\hline & Authors & Study design & Students' view & Teachers' view \\
\hline 1 & Wen, Yang, \& Rose, 2014 & Quantitative Method & $\mathrm{X}$ & \\
\hline 2 & Abeera \& Miri, 2014 & Mixed Methods & $\mathrm{X}$ & \\
\hline 3 & Khalil \& Ebner, 2013 & Quantitative Method & $\mathrm{X}$ & $\mathrm{X}$ \\
\hline 4 & $\begin{array}{l}\text { Masanet, Chang, Yao, Briam \& Huang, } \\
2014\end{array}$ & Quantitative Method & $\mathrm{X}$ & \\
\hline 5 & Najafi, Evans, \& Federico 2014 & Qualitative Method & $\mathrm{X}$ & \\
\hline 6 & Campbell, Gibbs, Najafi \& Severinski, 2014 & Quantitative Method & $\mathrm{X}$ & \\
\hline 7 & Espinosa, Sepulveda \& Montoya, 2015 & Mixed Methods & $\mathrm{X}$ & $\mathrm{X}$ \\
\hline 8 & Bruff, Fisher, McEwen \& Smith, 2013 & Mixed Methods & $\mathrm{X}$ & \\
\hline 9 & Nkuyubwatsi, 2013 & Qualitative Method & $\mathrm{X}$ & \\
\hline 10 & Bucovetchi, Simion \& Stanciu, 2015 & Qualitative Method & $\mathrm{X}$ & \\
\hline 11 & El Turk, 2015 & Mixed Methods & & $\mathrm{X}$ \\
\hline 12 & Loizzo, 2015 & Mixed Methods & $\mathrm{X}$ & \\
\hline 13 & Asiri, 2014 & Mixed Methods & $\mathrm{X}$ & \\
\hline 14 & Saadatmand \& Kumpulainen, 2014 & Mixed Methods & $\mathrm{X}$ & \\
\hline 15 & $\begin{array}{l}\text { Waite, Mackness, Roberts \& Lovegrove } \\
2013\end{array}$ & Mixed Methods & $\mathrm{X}$ & \\
\hline 16 & Milligan, Littlejohn \& Margaryan 2013 & Qualitative Method & $\mathrm{X}$ & \\
\hline 17 & $\begin{array}{l}\text { Patil, Raikar, Desai, Vijayalakshmi, Battur, } \\
\text { Parikshit \& Joshi, } 2016\end{array}$ & Qualitative Method & $\mathrm{X}$ & \\
\hline 18 & $\begin{array}{l}\text { Dal Magro, Gebing, Heinzmann, Romagna, } \\
\text { Studer, Goulart \& Imran, } 2017\end{array}$ & Quantitative Method & $\mathrm{X}$ & \\
\hline 19 & Tseng, Tsao, Yu, Chan \& Lai, 2016 & Mixed Methods & $\mathrm{X}$ & \\
\hline 20 & Leito, Helm \& Jalukse, 2015 & Qualitative Method & & $\mathrm{X}$ \\
\hline 21 & Eriksson, Adawi \& Stohr, 2017 & Qualitative Method & $\mathrm{X}$ & \\
\hline 22 & Leach \& Hadi, 2017 & Quantitative Method & $\mathrm{X}$ & \\
\hline 23 & Firmansyah \& Timmis, 2016 & Qualitative Method & & $\mathrm{X}$ \\
\hline 24 & Salvador \& Rodriguez-Hoyos, 2016 & Qualitative method & $\mathrm{X}$ & $\mathrm{X}$ \\
\hline 25 & $\begin{array}{l}\text { Fidalgo-Blanco, Sein-Echaluce \& } \\
\text { Garcia-Penalvo, } 2016\end{array}$ & Quantitative Method & $\mathrm{X}$ & \\
\hline 26 & Yousef, Chatti, Wosnitza \& Schroeder, 2015 & Mixed Methods & $\mathrm{X}$ & $\mathrm{X}$ \\
\hline 27 & $\begin{array}{l}\text { De la Garza, Sancho-Vinuesa \& Zermeno, } \\
2015\end{array}$ & Quantitative Method & $\mathrm{X}$ & $\mathrm{X}$ \\
\hline 28 & Pickering \& Swinnerton, 2017 & Quantitative Method & & $\mathrm{X}$ \\
\hline 29 & Mulumba, 2016 & Qualitative Method & $\mathrm{X}$ & \\
\hline 30 & Rohs \& Ganz, 2015 & Quantitative Method & & $\mathrm{X}$ \\
\hline 31 & Mamgain, Sharma \& Goyal, 2014 & Quantitative Method & $\mathrm{X}$ & \\
\hline 32 & Atrey, Parmar, Shiriskar \& Dhebar, 2016 & Mixed Methods & $X$ & $\mathrm{X}$ \\
\hline 33 & Linna, Mäkinen \& Keto, 2016 & Mixed Methods & $\mathrm{X}$ & $\mathrm{X}$ \\
\hline 34 & Lubis, Rosmansyah \& Supangkat, 2016 & Quantitative Method & $\mathrm{X}$ & \\
\hline 35 & Feng, Chen, Zhao, Chen \& Xi, 2015 & Quantitative Method & $\mathrm{X}$ & \\
\hline 36 & Sooryanarayan \& Gupta, 2015 & Quantitative Method & $\mathrm{X}$ & \\
\hline 37 & Gamage, Perera \& Fernando, 2015 & Quantitative Method & $\mathrm{X}$ & \\
\hline
\end{tabular}




\section{Results}

This study analyzed studies that were published and available from three scientific databases between January 2013 and July 2017. Additionally, the year 2015 was the most concentrated in terms of published studies with 12, while 2016 had 9 studies, and 2014 had 8 studies. In 2013 and 2017, there were only four studies. Most of the studies were published in western countries, such as the United States of America and Spain ( $\mathrm{n}=5$ for each), the United Kingdom and Germany ( $\mathrm{n}=3$ for each), and Mexico and Canada ( $\mathrm{n}=2$ for each). One study came from each of the following countries: Sweden, Romania, Rwanda, France, Finland, Estonia, Croatia, Brazil, and Austria. Moreover, India ( $n=5$ ), Indonesia ( $\mathrm{n}=2)$, and Israel ( $\mathrm{n}=1)$ also published some of these articles. According to the types of articles, three-fourths of the studies were published in journal articles $(n=26)$, while eight studies were published at conferences, and three studies were published as theses or dissertations (see Table 2).

Table 2. Basic Information About Studies

\begin{tabular}{lll}
\hline Year of Publication & & \\
\hline & $\mathrm{N}$ & Percentages \\
\hline 2013 & 4 & 10.81 \\
2015 & 8 & 21.62 \\
2016 & 12 & 32.43 \\
2017 & 9 & 24.32 \\
& 4 & 10.81 \\
\hline Country & 37 & 100 \\
\hline & & \\
\hline USA & $\mathrm{N}$ & Percentages \\
Spain & 5 & 13.51 \\
India & 5 & 13.51 \\
UK & 5 & 13.51 \\
Germany & 3 & 8.11 \\
Mexico & 3 & 8.11 \\
Indonesia & 2 & 5.41 \\
Canada & 2 & 5.41 \\
Sweden & 2 & 5.41 \\
Romania & 1 & 2.7 \\
Rwanda & 1 & 2.7 \\
Israel & 1 & 2.7 \\
France & 1 & 2.7 \\
Finland & 1 & 2.7 \\
Estonia & 1 & 2.7 \\
Croatia & 1 & 2.7 \\
Brazil & 1 & 2.7 \\
Austria & 1 & 2.7 \\
Type of Article & 1 & 2.7 \\
& 37 & 100 \\
\hline Journal article & & \\
Thesis/dissertation & $\mathrm{N}$ & Percentages \\
Conference proceeding & 26 & 70.27 \\
& 3 & 8.11 \\
& 8 & 21.62 \\
& 37 & 100 \\
\hline & & \\
& & \\
\hline
\end{tabular}

Table 3 shows the perspective of the studies that were collected for this study. Roughly two-thirds of the studies focused on the students' views of MOOCs with 25 studies (67.57\%), while students' and instructors' views of MOOCs came in the second rank with seven studies (18.92\%). The fewest studies were conducted with the instructors' view of MOOCs alone, only having five studies (13.51\%). 
Table 3. The Number of the Studies According to the Students and Instructors’ Views

\begin{tabular}{lll}
\hline & $\mathrm{N}$ & Percentages \\
\hline Students' views & 25 & 67.57 \\
students' and instructors' views & 7 & 18.92 \\
instructors' view & 5 & 13.51 \\
& 37 & 100 \\
\hline
\end{tabular}

\subsection{Students’ Views}

Leach and Hadi (2016) found that students gained recognition for their accomplishments when they were awarded achievement badges. They proposed a new way of categorizing the achievements of learners. Their method acknowledges micro learning, which is lacking in those other methods that only measure rates of completion.

Najafi et al. (2014) found that learners engaged with assessment and learning elements of an integrated online course in a manner that was highly dependent on self-study. They argued that their results are promising, especially when it comes to incorporating MOOCs in a self-study method in school-based programs. They stated that custom-making MOOCs could eliminate most of the existing challenges. Another study done by Mulumba (2016) revealed that the use of a VOKI (educational website) in the instruction process increased the learners' motivation and enhanced their engagement with the content. He concluded that the skills the students acquired were relevant to their working life. On the other hand, Milligan, Littlejohn \& Margaryan (2013) identified three types of engagement: lurking, passive participation, and active participation. They stated that the levels of engagement are affected by prior experience, confidence, and motivation. The results of their study revealed that the learning experience was influenced by the diverse range of students registered in such courses. Their findings can be used to make the learning experiences more suitable for all these students.

Wen, Yang and Rose (2014) reinforced that, based on their findings, the more motivation a student has, and the more individual participation he or she shows, the less likely it is that he or she will drop out from a course. In addition, Masanet, Chang, Yao, Briam and Huang (2014) indicated that web-based courses are sufficient to equip students with the fundamental skills of analysis. They also highlighted the various limitations of MOOCs, especially those related to "locked in" content. Furthermore, they stressed that online studies, especially MOOCs, can present opportunities for communities to effectively train and recruit their next generation of analysts. Another study done by Espinosa et al. (2015) classified its findings in four categories: challenges, problems, main contextual barriers, and connectivism. Some examples of challenges included the ability to self-motivate and self-regulate, and some examples of problems included limited information and IT skills. The main contextual barriers included some basic needs connected to the students' wellbeing not being met, and connectivism included the motivation of the students concerning the content of the online courses. They reinforced that the value of their study lies in the fact that they stress various important issues, including the need to promote connectivism and self-determination, effective learning, self-motivation, and self-regulation. Additionally, Sooryanaraayan and Gupta (2015) found that the preference for Made and Transfer MOOCs was affected by different motivation elements. They indicated that their results allow the designers of MOOCs to understand student motivation and to satisfy the needs of their consumers.

A study done by Mamgain, Sharma and Goyal (2014) showed that certain features in the Coursera and edX platforms of MOOCs to be very helpful in their studies, such as the ability to change the speed of a video. However, they did not favor some other features, such as having quizzes incorporated in a study video. They concluded that both variables are important, as they offer features that aim at empowering the students. However, Lubis, Rosmasyah and Supangkat (2016) found that there is some improvement gained from selecting several attributes, as this leads to decreasing errors in classification. They concluded that, for improved performance, further studies must combine the information derived from a course, the profiles of learners, and their experience. Magro et al. (2017) showed the students' acceptability of MOOCs that used a learning management system, as the design could improve their learning recovery process. They proposed an approach, referred to as Learning Management System (LMS), that could be useful in enhancing the learning recovery process of the learners.

The findings of Bucovetchi et al. (2015) were that the online study platforms are not remarkably popular among the study subjects because they are not interested in this type of education, as students wanted to gain more knowledge in their areas of study and other adjacent areas. They argued that the value of MOOC platforms comes from the easy and quick individual access to high-quality information in various disciplines. They also emphasized the importance of face-to-face contact between learners and instructors. In the study by Patil et al. (2016), participants discovered additional essential prerequisites that determine the performance of UX and Mobile UX, which are dependent on the 
construct and design. They argued that MOOCs could be incorporated in the curriculum to decrease the burden on tutors when it comes to assessment, teaching, and evaluations. They stated that MOOCs make it possible for instructors to concentrate on other academic tasks, such as course design and research. The results of a study carried out by Eriksson, Adawi and Stohr (2016) led to the identification of four key elements that influenced dropout rates: the learners' perception of the design of the course, their perception of the content of the course, their social characteristics and situation, and their ability to efficiently find time. Eriksson et al. (2016) found that the manner in which their students conceptualized or understood MOOCs had important implications for the manner in which they engaged with the study material. Additionally, they stated that their findings warrant further study, especially regarding certain specific themes, such as the identified dropout factors and the connection between dropout rates and course design.

The investigation of Bruff, Fisher, McEwen and Smith (2013) showed that while learners perceived some parts of the MOOC positively, they were worried about the blending of these courses with in-class elements. The results also suggested aspects for categorizing mixed study designs that use MOOCs. Moreover, they concluded that there is a need for more complicated forms of mixed-type learning of the course content that is derived from various MOOCs and other web-based sources. Their study suggested the intriguing possibility for categorizing faculty and student interactions, beyond any MOOC, to include interactions among media and online courses. However, Fidalgo-Blanco, Sein-Echaluce and Garcia-Penalvo (2016) found that completion rates for online courses were dependent on the students' perceptions of the learning experience quality.

Abeera and Miri's (2014) study found five competencies in learning that might affect the persistence, participation, and continuity of the learners in MOOCs: competence in the English language, being open-minded, self-efficacy, self-regulation, and having excellent skills of communication and prior knowledge of the study subject. Other influencers included the design features of the MOOCs, such as the clarity of the descriptions. They suggested that their results could be useful to educators, especially for the development of constructivist MOOCs. Moreover, Feng, Chen, Zhao, Chen and Xi (2015) found that the students who attained higher scores were usually very active on forums. Their results also showed that in online studies, the students who were likely to attain higher marks were those who wrote more course-related posts. In another study done by Saadatmand and Kumpulainen (2014), the results show the significantly high level of students' interaction using technology by MOOCs. They found that developing connections among professionals is a key advantage of taking part in the courses. Moreover, they pointed out that the findings of their study are essential, as they contribute to better comprehension of student participation in MOOCs and of the nature of learning.

Campbell, Gibbs, Najafi \& Severinski (2014) found that students had significant interest in the live online courses, and they depended on archived online courses to use as reference sources. In addition, they indicated that their results showed the significant potential for online courses to be very useful, as they combine the most valuable features of archived and live MOOCs to meet the interests and needs of the learners.

Gamage, Perera and Fernando (2015) found that student-related factors measure the effectiveness of these programs. These factors include motivation, opportunity network, interactivity, pedagogy, content, technology, and support for the student, as well as assessment. On the other hand, Tseng, Tsao, Yu, Chan, and Lai (2016) classified types of student behavior while taking part in the learning activities of the MOOC. Their findings suggested that timely feedback from facilitators and instructors on discussion forums could improve the engagement of students in MOOCs. In his dissertation, Loizzo (2015) found that the experience of adult students in online courses is often complex and that it happens within a democratic and dynamic social system of learning. He noted that his study results indicate the need for an instructional design of MOOCs that was learner-centered. His argument was that MOOCs need to appeal to a large assortment of adult learners.

Nkuyubwatsi (2013) highlighted the reappearing patterns and categorized them into five different themes: diversity, availability, interactivity, delivery, and openness. He also found that MOOCs are the most open programs, stating that the modes of these courses are empowering and that interaction with the content of an xMOOC (different types of MOOCs according to the taught subjects with advance level) can be supplemented with peer interaction. Moreover, Nkuyubwatsi (2013) stated that xMOOCs can be useful in mitigating the issue of higher education tutor shortage and financial difficulties in Rwanda, as they can empower Rwandese learners and students and enable network maintenance and creation. Waite, Mackness, Roberts, and Lovegrove (2013) identified three important themes in their data: navigation issues, transformative learning issues, and reciprocal relationships. They concluded that engaging the local expertise of MOOC learners who are experienced and designing participatory skills with students are effective strategies for those who facilitate and organize MOOCs.

A study done by Asiri (2014) found various differences and similarities between US and international graduate learners. 
Learners in both categories use online courses to supplement their usual studies. The MOOCs were found to be very useful in increasing the students' knowledge in the subject areas. Examples of some differences included that international learners may use the courses to improve their proficiency in English and become familiar with the American academic system before attending a school in the US. The researcher found that MOOCs could be effective supplemental tools that students can use to increase their knowledge and improve their overall performance.

\subsection{Instructors' Views}

El Turk (2015) carried out a study to identify the perceived barriers limiting or barring the implementation by faculty and administrators of online education using an online survey tool. The author used the exploratory factor-analysis method and identified eight different factors from the 35 perceived online education barriers. These included pedagogical barriers, interpersonal barriers, cost-effective analysis barriers, and technical ones. Status, role, and working experiences were found to affect the perceptions of administrators of the cultural, epistemological, and structural barriers. Alternatively, rank and age were found to affect the faculty's perceptions of the psychological and technical barriers. In addition, El Turk indicated that the findings inform the relevant stakeholders about ways that allow the effective implementation of online courses in higher education, especially in institutions in Lebanon. The researcher pointed out that the findings could be very important for these institutes, especially those that implemented online training in their programs.

Rohs and Ganz (2015) examined a common claim regarding MOOCs, which states that the aim of open education resources is to expand education access, particularly in higher education institutions. Their work aimed at finding out whether MOOCs have met this claim. The researchers made use of the data collected from participants of two MOOCs. The data and information confirmed the researchers' suspicion that despite the participants' heterogeneity, MOOCs are mainly utilized by individuals who have a higher level of education. Moreover, they found that MOOCs are mainly utilized by individuals who already have certification from higher education institutions. The researchers indicated that one reason for this commonality might be due to the courses themselves, as they offer courses mainly meant for higher education students. As the authors indicated, several barriers, such as usage and access, lead to disadvantages for these individuals as compared to those who have a higher socioeconomic or educational status. Based on the knowledge gap theory, MOOCs usually contribute to increasing and reinforcing the existing inequalities in education rather than helping to decrease them. The paper stressed the importance of addressing educationally disadvantaged people in light of the public investment issue.

In their work, Leito, Helm, and Jalukse (2015) presented the experience of running a MOOC program at a higher education facility. They compared training and teaching using the MOOC model to the traditional university program, as well as to short training courses used to educate professionals. The findings of the study indicated that the students participated actively in MOOCs and stated they had a positive experience. Furthermore, the discussion thread offered by the courses provided significant added value to the educational material; and, in some cases, the discussion triggered changes to the course materials. The participants' feedback was notably positive. On the other hand, Leito et al. (2015) indicated that due to uncertainties in measurement in analytical chemistry, MOOCs are not legitimate competitors for conventional programs used in universities. They added that in the context of training or practitioners, MOOCs can provide important advantages and that the teaching materials used in MOOCs can be used as support materials for traditional teaching in higher education institutions.

Alternatively, Firmansyah and Timmis (2016) wrote an article whose main aim was to provide a report of a qualitative study carried out to examine and understand what actually occurs in the IDCourseians, which is an independent learning community in Indonesia. Additionally, they further discussed their findings in relation to the community of practice and collaborative learning. The authors concluded that, where English is not the main language of communication, and where the hub model is not yet in use, developing face-to-face communication within local communities must be a priority. The paper indicated that this offers a potential strategy to overcome some common challenges of MOOCs, including the lack of motivation and challenges in interpreting the course material. In their work, Pickering and Swinnerton (2017) intended to provide useful information by utilizing an anatomy MOOC to review and examine the patterns of engagement, demographic profile, and self-perceived advantages for professionals in health care. The main objective of joining the program for all professionals was to learn and gain new information in relation to clinical practice. The study examined the students' engagement and self-perception of MOOCs. The findings indicated a notably high level of involvement in the courses. The study showed that this level of involvement can be achieved by adopting a type of MOOC supported with content that is specifically targeted for the healthcare industry. The authors suggested that this learning tool type should further be investigated as a way of continuing interprofessional and professional education. 


\subsection{Students and Instructors' Views}

Khalil and Ebner (2015) investigated the significance and contentment of the interaction rate in MOOCs as indicated by instructors and learners. The reports regarding the availability of various criteria recommended by Salmon (2001) were found to be negative. Additionally, the investigation showed that instructors and students considered the MOOCs as being highly satisfactory. However, some learners indicated that they were only slightly satisfied with the interaction that MOOCs offered and reported their discontent with the low level of interaction with instructors. That being said, their study revealed that "there is a notable gap between the students' satisfaction and perceptions of MOOC interaction, on the one hand, and instructors' satisfaction and perception of using MOOCs" (P. 637). The researchers suggested that the instructors could enhance the interaction between students and instructors and increase student satisfaction by seeking the help of trained teaching assistants. Furthermore, it was suggested that instructors could utilize peer-based assessment, instead of computer-based assessment, to improve the interaction.

Salvador and Rodriguez-Hoyos (2016) carried out a study with the aim of analyzing the MOOC phenomenon with pedagogical criteria. All of the work was grouped under three phases: "the theoretical design and review of the classroom activities, the development of a MOOC best practice guide, and the implementation of these activities as well as the review of the key results" (P.1). The results demonstrated the need to implement and introduce MOOCs, especially in bachelor's courses in the field of education. Also, it is important to update the courses that students take at universities for updating the courses' design, not just for using the new technology. On the other hand, they found that the analysis was not only positive from the students' viewpoint, but that It gave the teachers a chance to build the relationship between educational improvement and research. This constructed "rich pedagogical practices that provided the environments in which students develop skills increasingly in demand in the labor market, while simultaneously helping to create and build communities of practice” (P. 8).

According to the researchers, this is essential, as it promotes the development of comprehensive instructive activities that create settings whereby learners can acquire skills that are becoming increasingly important in the job market while helping to build and create practice communities at the same time. These communities were shown an important role, as they are where university professionals can discuss, and share their opinions on MOOCs with the general goal of enhancing education in universities to implement technology. (Salvador \& Rodriguez-Hoyos, 2016).

In their work, Atrey, Parmar, Shiriskar and Dhebar (2016) reviewed the model used by the Train Ten Thousand Teachers or T10kT team to inspect and review the findings from the fifteen synchronous courses. These questions were related to issues such as distance learning and T10kT, whether T10kT provides motivation for learning, and the perceptions of the instructors regarding the instruction. The researchers found that 127 institutions have participated recurrently in the program and that $92 \%$ of the teachers who were part of the program in the second phase courses found the program experience to be very beneficial. Atrey et al. (2016) concluded that the T10kT model is an excellent and ideal choice, especially for institutions that aim to improve teacher professional development.

The study of De La Garza et al. (2015) discussed the pedagogical, functional, technological, and time factors of using MOOCs and was designed to provide the teachers with a training program through MOOCs. The results shed light on the importance of the program design according to the participants' evaluation. The study used an evaluation of the quality indicators mentioned above to examine the success of MOOCs for the training program. The researchers believed that the success of using MOOCs cannot be decided unless these indicators were measured. The study stated that time is an essential factor that affected the pedagogical quality of MOOCs, and it also related to the effectiveness between pedagogical, functional, and technological factors. This is because the more the use of technology advances, the more that education of advanced constructivism learning is considered a challenge with the different learning styles. Therefore, MOOCs could be used to evaluate the teachers' training.

Since MOOCs have a distinctive feature of using effective technology, Yousef et al. (2015) were interested in studying the challenges of the development of MOOCs. They examined the reasons behind the high dropout rate percentage of students from these courses. The results showed there were several reasons: "blended learning, flexibility, high quality content, instructional design and learning methodologies, lifelong learning, network learning, openness, and student-centered learning from students' perspectives” (P.75), in addition to cultural and demographic reasons. In other words, the results showed that the challenges of using MOOCs were the cultural background of the participants as well as their motivation for using MOOCs, such as the complexity and diversity of the participants in MOOCs.

Linna, Makinen, and Keto (2016) also reviewed MOOCs and examined their use from various viewpoints. In their study, the researchers also discussed the in-house training of company personnel. According to them, the issue related to finding the proper ways of using third-party MOOCs in these three areas. Based on the investigation, an MUPM (MOOC Utilization Preliminary Model) was created to present the numerous MOOC opportunities for education 
organizers, teachers, and companies that are not yet using the model. However, Linna et al. (2016) pointed out that MOOC concepts would continue developing in the future. They indicated that the challenge would have to do with who would take the trophy when it comes to the competition for the course and platform supply and quality. Their key recommendation, especially for small institutions, was that they must exploit MOOCs and use them in a blended or mixed learning model, as the strategy is a key element in providing students with new and flexible forms when it comes to the implementation of study methods, especially in their professional life.

\section{Discussion and Findings}

Many scholars focused on MOOCs as a trend in technology and paid attention to how MOOCs are able to provide a good environment for the students to learn and improve their knowledge and skills. Some scholars measured students' and instructors' views of MOOCs to identify their experience using MOOCs with different settings (Bruff et al., 2013; Asiri, 2014; Saadatmand \& Kumpulainen, 2014; Waite et al., 2013; Patil et al., 2016; Leito et al., 2015; Leito et al., 2015; Eriksson et al., 2017; Salvador \& Rodriguez-Hoyos, 2016), perception (Abeera \& Miri, 2014; Espinosa et al., 2015; El Turk, 2015; Loizzo, 2015; Saadatmand \& Kumpulainen, 2014; Dal Magro et al., 2017; Firmansyah \& Timmis, 2016; Mamgain et al., 2014), motivation (Wen et al., 2014; Pickering \& Swinnerton, 2017; Atrey et al., 2016; Sooryanarayan \& Gupta, 2015), performance (Masanet et al., 2014; Nkuyubwatsi, 2013; Yousef, et al., 2015; Gamage et al., 2015), engagement (Milligan et al., 2013; Pickering \& Swinnerton, 2017; Mulumba, 2016), preference (Abeera \& Miri, 2014; Mamgain et al., 2014; Atrey et al., 2016), satisfaction (Fidalgo-Blanco et al., 2016; Khalil \& Ebner, 2013), interaction (Khalil \& Ebner, 2013), behavior (Campbell et al., 2014; Leach \& Hadi, 2017), awareness (Bucovetchi et al., 2015), and intent (Campbell et al., 2014). This variation can help the researchers evaluate the MOOC and know more about how MOOCs could become an official method of education in the world. Most of these studies applied surveys to identify their variables and goals with different instruments and settings (e.g., Campbell et al., 2014; Leach \& Hadi, 2017; Bruff et al., 2013; Asiri, 2014; Saadatmand \& Kumpulainen, 2014; Waite et al., 2013; Patil et al., 2016; Leito et al., 2015; Eriksson et al., 2017; Salvador \& Rodriguez-Hoyos, 2016). In addition, some studies used the case studies method and semi-interview methods. These are considered the second most interesting type of research for the scholars to explore students' views and instructors' views toward the use of MOOCs (e.g. Najafi et al., 2014; Bruff et al., 2013; Loizzo, 2015; Patil et al., 2016; Dal Magro et al., 2017; Eriksson et al., 2017; Leach \& Hadi, 2017; Firmansyah \& Timmis, 2016; Salvador \& Rodriguez-Hoyos, 2016; Linna et al., 2016).

Studies considering the students' views aimed at finding the MOOCs that best worked for students. Some studies agreed that student engagement and dropout rates were the most important measurements of an effective MOOC (Najafi et al., 2014; Mulumba, 2016). Moreover, most of the studies agreed that MOOCs are useful courses because they offer openness, flexibility, ease of access, interactivity, and good design (Nkuyubwatsi, 2013; Yousef et al., 2015). When the factors are met, students find it easy to use MOOCs as supplementary study tools. In addition, when MOOCs are well designed, it helps motivate students to learn, and they prefer these courses to improve their knowledge and skills (Sooryanaraayan \& Gupta, 2015; Espinosa et al., 2015; Wen et al., 2014). In some studies, students' perceptions of MOOCs were measured, and the results showed that students positively perceived these courses (Bruff et al., 2013) and typically complete their courses (Fidalgo-Blanco et al., 2016).

Studies considering the instructors' views acknowledged the importance of online courses in education, especially in an era where technology continues to influence the lives of individuals. All the studies look at one particular way that higher education institutions can ensure that online education is effectively implemented in school curricula to ensure success in performance and education. El Turk (2015) indicated that online courses may be a solution for many students, especially in an era where education has become constricted by different factors, such as family responsibilities, disabilities, distance from campus, personal issues, and finances.

Leito, Helm, and Jalukse (2015) added that MOOCs could be vital as add-ons, especially in chemistry education. They stated that MOOCs offer important advantages over the traditional intensive course formats and that they could be vital as support materials for higher education teaching. Just like the other authors, Firmansyah and Timmis (2016) agreed that MOOC courses could be effective teaching tools. They also agreed that various problems exist that limit their effectiveness and must be addressed. Their suggestion was that MOOC educational institutions and providers must help in developing face-to-face communities, especially in contexts where locals do not speak English, in order to help the learners improve their interactions and engage with the international MOOC courses, as this might be an excellent way for them to experience the courses and make their studies more meaningful. Rohs and Ganz (2015) stressed that MOOCs could be used as a marketing tool for universities rather than as an educational tool. They reinforced that this should be corrected so that MOOCs can address the educational needs of all, especially the disadvantaged. 
The students' and instructors' view studies seem to agree that MOOCs are important courses and education programs for improving student learning. They also seem to agree on the importance of evaluating MOOCs, particularly to investigate the gaps that limit the courses when it comes to improving educational outcomes. For example, Khalil and Ebner (2015) agreed that MOOCs are important educational tools. Simultaneously, they pointed out that they could be improved. Salvador et al. (2016) indicated the need to increase the number of studies focused on analyzing MOOCs so as to improve higher education teaching. Yousef et al. (2015) agreed that MOOCs are important teaching tools and pointed out that they could be improved by coming up with hybrid MOOCs. De la Garza et al. (2015) also emphasized the importance of evaluation of the quality of the courses presented in MOOCs. Their study results indicated that only through these evaluations can the pedagogical quality of MOOCs be measured by institutions.

\section{Conclusion and Recommendations}

This research was conducted on Massive Online Open Courses (MOOCs) studies from January 2013 till July 2017 to provide an exciting review of the understanding of use of MOOCs and students' and instructors' opinions of MOOCs. It also discussed the results of 37 studies that the researchers analyzed according to the methodology used in this paper. The results showed that there are many studies focused on three pillars: students' views, instructors' views, and students' and instructors' views. These three pillars were considered the most important to review and focus on in the attempt to understand the use of MOOCs and their development. According to the students' views results, there is a difference of student numbers in MOOCs between those who registered at the beginning of the course and those who registered at the end of sessions (Wen et al., 2014). According to the results, it is very important to explore and examine students' perspectives of MOOCs. , using a mixed method research to have richer data of students' view toward MOOCs can determine the reasons why students drop out from these courses after they enrolled (Bruff et al., 2013). Moreover, it is very important to see students' opinions of the content that is being delivered to the students, to understand how students interact with their instructors or among students, and to identify how instructional design can affect their learning in a MOOC (Bucovetchi et al., 2015). In addition to this, the design of MOOCs is considered a very important point; therefore, measuring students' opinions of the course design would guide the instructors and designers to provide a good learning environment for MOOCs (Saadatmand \& Kumpulainen, 2014; Campbell et al., 2014).

Many scholars mentioned that MOOCs make it easy to access course materials in different subjects, such as medicine, engineering, science, and history (Bucovetchi et al., 2015; Masanet et al., 2014). This encourages students who are eager to improve their knowledge and skills to attend these courses (Yousef et al, 2015). Thus, government universities and colleges should support this new learning method, provide it with qualified instructors (Salvador \& Rodriguez-Hoyos, 2016; Leito et al., 2015; El Turk, 2015), and provide free resources of courses and training programs for participants.

According to the results, there is a lack of studies focused on the students' and instructors' view. Therefore, it is imperative to identify the instructors' role in this method to help students in their learning and have a clear view about the instructors' perceptions of MOOCs. The decline in student numbers at the end of the course could be caused by the instructors' role, or perhaps the instructors need more professional development (Pickering \& Swinnerton, 2017). Technical issues that faced the instructors might also cause students to drop out of the courses (Khalil and Ebner, 2015). MOOC instructors should have knowledge that helps them avoid any technical issues in their teaching.

All in all, there is a lack of research into students' and instructors' views and instructors' views. Therefore, there is a need for more studies that examine and explore the use of MOOCs in order to have a clear picture. Also, the effectiveness of instructional design should be examined to determine the effect of design on students' performance and interaction.

\section{References}

Abeera, W., \& Miri, B. (2014). Students' preferences and views about learning in a MOOC. Procedia-Social and Behavioral Sciences, 152, 318-323. https://doi.org/10.1016/j.sbspro.2014.09.203

Asiri, O. I. Y. (2014). A Comparison Between International and US Graduate Students' Attitudes and Experiences Using Massive Open Online Courses (MOOCs). Rochester Institute of Technology.

Atrey, M., Parmar, M., Shiriskar, R., \& Dhebar, K. (2016). T10kT: Scaling up Professional Development of Teachers: Evidences and Recommendations from Large Scale Implementation. In Learning and Teaching in Computing and Engineering (LaTICE), 2016 International Conference on (pp. 81-88). IEEE. 
https://doi.org/10.1109/LaTiCE.2016.43

Barak, M., Watted, A., \& Haick, H. (2016). Motivation to learn in massive open online courses: Examining aspects of language and social engagement. Computers \& Education, 94, 49-60. https://doi.org/10.1016/j.compedu.2015.11.010

Battur, S., Patil, M. S., Desai, P., Vijayalakshmi, M., Raikar, M. M., Hegde, P., \& Joshi, G. H. (2016). Enhancing the students project with Team Based learning approach: a case Study. In MOOCs, Innovation and Technology in Education (MITE), 2016 IEEE 4th International Conference on(pp. 275-280). IEEE. https://doi.org/10.1109/MITE.2016.061

Bruff, D. O., Fisher, D. H., McEwen, K. E., \& Smith, B. E. (2013). Wrapping a MOOC: Student perceptions of an experiment in blended learning. Journal of Online Learning and Teaching, 9(2), 187.

Bucovetchi, O. M. C., Simion, C. P., \& Stanciu, R. D. (2015). The newest trend in personal development-MOOC platforms. In The International Scientific Conference eLearning and Software for Education (Vol. 2, p. 404). " Carol I" National Defence University.

Campbell, J., Gibbs, A. L., Najafi, H., \& Severinski, C. (2014). A comparison of learner intent and behaviour in live and archived MOOCs. The International Review of Research in Open and Distributed Learning, 15(5). https://doi.org/10.19173/irrodl.v15i5.1854

Carson, S., \& Schmidt, J. (2012). The massive open online professor academic matter. Retrieved $23^{\text {rd }}$ December, 2017, from http://www.academicmatters.ca/2012/05/the-massive-open-online-professor/

Cormier, D., \& Siemens, G. (2010). Through the Open Door: Open Courses as Research, Learning, and Engagement. EDUCAUSE Review, 45, 30-39.

Dal Magro, E., Gebing, S., Heinzmann, L., Romagna, M. E., Studer, J., Goulart, T. M., \& Imran, H. (2017). MOOC as Supplementary Tutoring to Public School Students Learning. In Advanced Learning Technologies (ICALT), 2017 IEEE 17th International Conference on (pp. 220-223). IEEE. https://doi.org/10.1109/ICALT.2017.158

de la Garza, L. Y. A., Sancho-Vinuesa, T., \& Zermeño, M. G. G. (2015). Indicators of pedagogical quality for the design of a Massive Open Online Course for teacher training. International Journal of Educational Technology in Higher Education, 12(1), 104-118. https://doi.org/10.7238/rusc.v12i1.2260

El Turk, S. (2015). Perceived online education barriers through the voices of administrators and faculty at a US university in Lebanon (Doctoral dissertation, Creighton University).

Epelboin, Y. (2013). MOOC in Europe. UPMC-Sorbonne University.

Eriksson, T., Adawi, T., \& Stöhr, C. (2017). "Time is the bottleneck”: a qualitative study exploring why learners drop out of MOOCs. Journal of Computing in Higher Education, 29(1), 133-146. https://doi.org/10.1007/s12528-016-9127-8

Espinosa, B. J. G., Sepúlveda, G. C. T., \& Montoya, M. S. R. (2015). Self-motivation challenges for student involvement in the Open Educational Movement with MOOC. International Journal of Educational Technology in Higher Education, 12(1), 91-103.

Espinosa, B. J. G., Sepúlveda, G. C. T., \& Montoya, M. S. R. (2015). Self-motivation challenges for student involvement in the Open Educational Movement with MOOC. International Journal of Educational Technology in Higher Education, 12(1), 91-103.

Feng, Y., Chen, D., Zhao, Z., Chen, H., \& Xi, P. (2015). The impact of students and TAs' participation on students' academic performance in MOOC. In Proceedings of the 2015 IEEE/ACM International Conference on Advances in Social Networks Analysis and Mining 2015 (pp. 1149-1154). ACM. https://doi.org/10.1145/2808797.2809428

Fidalgo-Blanco, Á., Sein-Echaluce, M. L., \& García-Peñalvo, F. J. (2016). From massive access to cooperation: lessons learned and proven results of a hybrid xMOOC/cMOOC pedagogical approach to MOOCs. International Journal of Educational Technology in Higher Education, 13(1), 24. https://doi.org/10.1186/s41239-016-0024-z

Firmansyah, M., \& Timmis, S. (2016). Making MOOCs meaningful and locally relevant? Investigating IDCourserians - an independent, collaborative, community hub in Indonesia. Research and Practice in Technology Enhanced Learning, 11(1), 11. https://doi.org/10.1186/s41039-016-0032-6 
Gamage, D., Perera, I., \& Fernando, S. (2015). A Framework to analyze effectiveness of eLearning in MOOC: Learners perspective. In Ubi-Media Computing (UMEDIA), 2015 8th International Conference on (pp. 236-241). IEEE. https://doi.org/10.1109/UMEDIA.2015.7297461

Khalil, H., \& Ebner, M. (2015). “How Satisfied Are You With Your MOOC?”-A Research Study About Interaction in Huge Online Courses. Journalism and Mass Communication, 5(12), 629-639. https://doi.org/10.17265/2160-6579/2015.12.003

Koller, D. (2012). What we're learning from online education. TED talk,(June).

Kop, R., \& Carroll, F. (2011). Cloud computing and creativity: Learning on a massive open online course. European Journal of Open, Distance and E-learning, 14(2).

Leach, M., \& Hadi, S. M. (2017). Supporting, categorising and visualising diverse learner behaviour on MOOCs with modular design and micro-learning. Journal of Computing in Higher Education, 29(1), 147-159. https://doi.org/10.1007/s12528-016-9129-6

Leito, I., Helm, I., \& Jalukse, L. (2015). Using MOOCs for teaching analytical chemistry: experience at University of Tartu. Analytical and bioanalytical chemistry, 407(5), $1277-1281$. https://doi.org/10.1007/s00216-014-8399-y

Linna, P., Mäkinen, T., \& Keto, H. (2016). Utilizing MOOCs in the development of education and training programs. In Information and Communication Technology, Electronics and Microelectronics (MIPRO), 2016 39th International Convention on (pp. 861-864). IEEE. https://doi.org/10.1109/MIPRO.2016.7522260

Loizzo, J. L. (2015). Adult learners' perceptions of MOOC motivation, success, and completion: a virtual ethnographic study (Doctoral dissertation, Purdue University).

Lubis, F. F., Rosmansyah, Y., \& Supangkat, S. H. (2016). Experience in learners review to determine attribute relation for course completion. In ICT For Smart Society (ICISS), 2016 International Conference on (pp. 32-36). IEEE. https://doi.org/10.1109/ICTSS.2016.7792865

Mackness, J., Waite, M., Roberts, G., \& Lovegrove, E. (2013). Learning in a small, task-oriented, connectivist MOOC: Pedagogical issues and implications for higher education. The international review of research in open and distributed learning, 14(4). https://doi.org/10.19173/irrodl.v14i4.1548

Mak, S., Williams, R., \& Mackness, J. (2010). Blogs and forums as communication and learning tools in a MOOC. Retrieved from https://www.lancaster.ac.uk/fss/organisations/netlc/past/nlc2010/abstracts/PDFs/Mak.pdf

Mamgain, N., Sharma, A., \& Goyal, P. (2014). Learner's perspective on video-viewing features offered by MOOC providers: Coursera and edX. In MOOC, Innovation and Technology in Education (MITE), 2014 IEEE International Conference on (pp. 331-336). IEEE. https://doi.org/10.1109/MITE.2014.7020298

Masanet, E., Chang, Y., Yao, Y., Briam, R., \& Huang, R. (2014). Reflections on a massive open online life cycle assessment course. The International Journal of Life cycle Assessment, 19(12), $1901-1907$. https://doi.org/10.1007/s11367-014-0800-8

McAuley, A., Stewart, B., Siemens, G., \& Cormier, D. (2010). Massive open online courses digital ways of knowing and learning. Retrieved 23 ${ }^{\text {rd }}$ December, 2017, from http://www.elearnspace.org/Articles/MOOC_Final.pdf

Milligan, C., Littlejohn, A., \& Margaryan, A. (2013). Patterns of engagement in connectivist MOOCs. Journal of Online Learning and Teaching, 9(2), 149.

Mulumba, M. B. (2016). Improving student teachers’ knowledge-base in language education through critical reading. Pedagogy, Culture \& Society, 24(4), 571-586. https://doi.org/10.1080/14681366.2016.1196233

Najafi, H., Evans, R., \& Federico, C. (2014). MOOC integration into secondary school courses. The International Review of Research in Open and Distributed Learning, 15(5). https://doi.org/10.19173/irrodl.v15i5.1861

Nkuyubwatsi, B. (2013). Evaluation of massive open online courses (MOOCs) from the learner's perspective. In European Conference on e-Learning (p. 340). Academic Conferences International Limited.

Pickering, J. D., \& Swinnerton, B. J. (2017). An anatomy massive open online course as a continuing professional development tool for healthcare professionals. Medical Science Educator, 27(2), $243-252$. https://doi.org/10.1007/s40670-017-0383-7

Rohs, M., \& Ganz, M. (2015). MOOCs and the claim of education for all: A disillusion by empirical data. The International Review of Research in Open and Distributed Learning, 16(6). 
https://doi.org/10.19173/irrodl.v16i6.2033

Saadatmand, M., \& Kumpulainen, K. (2014). Participants' perceptions of learning and networking in connectivist MOOCs. Journal of Online Learning and Teaching, 10(1), 16.

Salvador, A. C., \& Rodríguez-Hoyos, C. (2016). Analizying MOOCs from an educational perspective in Spain. International Journal of Educational Technology in Higher Education, 13(1), 13. https://doi.org/10.1186/s41239-016-0005-2

Sooryanarayan, D. G., \& Gupta, D. (2015). Impact of learner motivation on mooc preferences: Transfer vs. made moocs. In Advances in Computing, Communications and Informatics (ICACCI), 2015 International Conference on (pp. 929-934). IEEE. https://doi.org/10.1109/ICACCI.2015.7275730

Tseng, S. F., Tsao, Y. W., Yu, L. C., Chan, C. L., \& Lai, K. R. (2016). Who will pass? Analyzing learner behaviors in MOOCs. Research and Practice in Technology Enhanced Learning, 11(1), 8. https://doi.org/10.1186/s41039-016-0033-5

Wen, M., Yang, D., \& Rosé, C. P. (2014). Linguistic Reflections of Student Engagement in Massive Open Online Courses. In ICWSM.

Yousef, A. M. F., Chatti, M. A., Schroeder, U., \& Wosnitza, M. (2015). A usability evaluation of a blended MOOC environment: An experimental case study. The International Review of Research in Open and Distributed Learning, 16(2). https://doi.org/10.19173/irrodl.v16i2.2032 